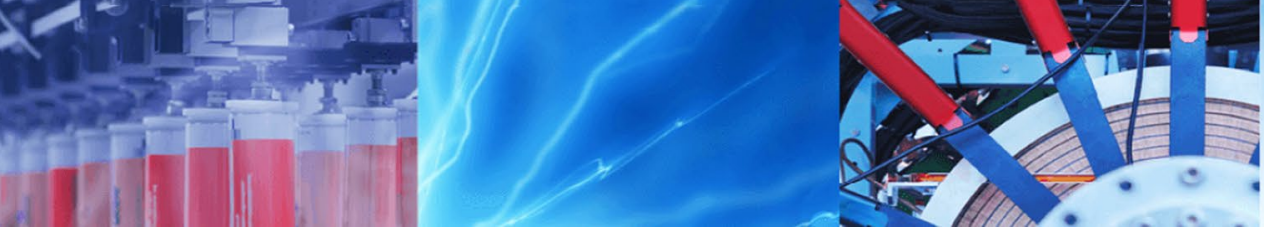

Research Article

\title{
Synthesizing and comparing $\mathrm{HA}-\mathrm{TiO}_{2}$ and $\mathrm{HA}-\mathrm{ZrO}_{2}$ nanocomposite coatings on 316 stainless steel
}

\author{
Morteza Poorraeisi $^{1} \cdot$ Abdollah Afshar $^{1}$
}

(c) Springer Nature Switzerland AG 2019

\begin{abstract}
In this research, hydroxyapatite coating and composite hydroxyapatite coatings containing nanoparticles were fabricated using a single step electrodeposition method. To investigate the effect of compositing agent type on hydroxyapatite structure, two different compounds (titania and zirconia) were used. Each compound was used at two different concentrations to observe the effect of compositing agent content on matrix structure. Pure hydroxyapatite was deposited with a water based Calcium-Phosphate ( $\mathrm{Ca}-\mathrm{P})$ solution with $\mathrm{pH}=4.2$. To deposit composite coatings, a merged solution was prepared by merging $\mathrm{Ca}-\mathrm{P}$ solution with aqueous $\mathrm{TiO}_{2}\left(\mathrm{ZrO}_{2}\right)$ suspension. Prepared coatings were analyzed using thickness measurement, XRD, FTIR, FESEM, polarization test and immersion in SBF solution. In the first step, XRD, FTIR and FESEM results proved the formation of hydroxyapatite using $\mathrm{Ca}-\mathrm{P}$ solution and analysis of composite coatings proves the existence of nanoparticles in the coatings as compositing agent and the coating procedure was successful. Thereafter, polarization and immersion results indicate that composite coatings show superior properties than pure hydroxyapatite. The properties of hydroxyapatite matrix are influenced not only by the type of the compositing agent but also by the content of the additive. Adding nanoparticles changes different characteristics of pure HA, such as (1) decreasing the thickness of the coating, pure hydroxyapatite was $5.5 \mu \mathrm{m}$ and the thickness of $\mathrm{HA}-\mathrm{ZrO}_{2}\left(\mathrm{ZrO}_{2}: 6 \mathrm{mM}=\mathrm{HZ}_{2}\right)$ composite coating was $4.4 \mu \mathrm{m}$; (2) increasing the crystallinity (Xc), $\mathrm{Xc}$ for $\mathrm{HZ}_{2}$ coating is $86 \%$ and $\mathrm{Xc}$ for pure $\mathrm{HA}$ is $80 \%$; (3) obvious changes in morphology has occurred and new morphologies of $\mathrm{HA}$ are observed which has not been mentioned in the literature previously; (4) composite coatings have more positive $\mathrm{E}_{\text {corr }}$ than pure $\mathrm{HA}, \mathrm{E}_{\text {corr. }}$ of $\mathrm{HZ}_{2}$ coating is -0.23 which is the most positive one and $\mathrm{E}_{\text {corr. }}$ of $\mathrm{HA}$ is -0.41 ; (5) composite coatings have smaller porosity ratio than pure $\mathrm{HA}$; (6) Pure and composite coatings are bioactive, but composite coatings show different bioactivity behavior.
\end{abstract}

Keywords Biomaterial $\cdot$ Biocoating $\cdot$ Composite $\cdot$ Nano $\cdot$ Synthesis $\cdot$ Electrochemistry

\section{Introduction}

Metallic and ceramic biomaterials such as stainless steels (SS), titanium and its alloys and hydroxyapatite have clinical and orthopedic attention and use [1-3]. On one hand, metallic alloys have high strength, formability, chemical durability and resistance to corrosion in physiological environment $[1,4]$, but there is a big drawback, chemical mismatch with human or animal body tissues which bans successful growth of bone tissue on orthopedic implants
$[4,5]$. On the other hand, bioceramics such as hydroxyapatite $\left.\left(\mathrm{HA}: \mathrm{Ca}_{10}\left(\mathrm{PO}_{4}\right)_{6}\right) \mathrm{OH}_{2}\right)$ have really good chemical and structural match with natural human bone $[1,6]$, but there is a weak point, mechanical mismatch with natural bone. To completely treat bone injuries, fixation and immobilization of the injured tissue (good mechanical properties) and preferable medium for the tissue growth (good bioactivity and biocompatibility) are necessary. The former requirement is achieved using metallic biomaterials and the later one is achieved using bioceramics, therefore, to

Morteza Poorraeisi, morteza.poorraeisi@gmail.com | ${ }^{1}$ Department of Materials Science and Engineering, Sharif University of Technology, Azadi Avenue, P.O. Box 11155-9466, Tehran, Iran.

SN Applied Sciences (2019) 1:155 | https://doi.org/10.1007/s42452-019-0168-2

Received: 8 November 2018 / Accepted: 4 January 2019 / Published online: 8 January 2019

SN Applied Sciences

A SPRINGER NATURE journal 
reach a great combination of these two requirements, composite implants are suggested. For example using hydroxyapatite as coating on metallic implants which provides all the necessities of an implant $[4,7]$ that extremely reduces treatment period [7]. There are several approaches to deposit HA on metallic substrates such as plasma spray [8], cold spray [9], laser-pulse deposition [10], high velocity oxy-fuel (HVOF) [11], electrophoretic and electrochemical deposition [12, 13]. Electrodeposition (ED) of hydroxyapatite has recently aroused widespread concern owning to many advantages of the technology, specially comparing the electrodeposition with other coating methods. Such as advantages are: (1) Low temperature deposition process which results in better control on the coating composition and purification of the phases $[8,11,14]$; (2) Simultaneous synthesize and deposition of the coating which is a great benefit over plasma spray deposition, cold spray deposition and HVOF deposition methods that synthesize and coating procedure are separated $[8,9,11] ;(3)$ no need for pre/post treatments such as heat treatments $[4,9]$ and chemical treatments $[15,16]$; and (4) the ease to control the film performance, the capacity to deposit on complicated surfaces, the usability, simple and common equipment, chemical and morphological control on deposited coating and low price of device $[3,14,17,18]$. The cathodic deposition of Ca-P coating is done using the ambient temperature that results in good conformability to the shape of the component [19]. Sometimes, the deposition is carried out at higher temperatures but these seldom exceed $100^{\circ} \mathrm{C}$ most of the time electrodeposition is completed by a single step of direct HA formation, sometimes, the process is comprised of two steps also [14]. Furthermore, to effectively improve the properties of hydroxyapatite such as bioactivity, biocompatibility, antibacterial behavior, osseointegration and crystallinity, different approaches are used. For example, doping with useful elements like silver and copper; and compositing with special compounds like alginate, bioglass, bioceramics and biopolyemrs [20-23]. In this study, titania and zirconia are used as composite agent. Titania is one of the most useful and common ceramics for orthopedic applications, that is bioactive oxide increasing bone formation on implants and is extensively attended to produce biocomposite coatings [24, 25]. Zirconia is biocompatible and bioinert compound, recently used to improve pure $\mathrm{HA}$ specifications such as corrosion resistance, bioactivity and crystallinity of $\mathrm{HA}[3,8,26,27]$. To make $\mathrm{HA}-\mathrm{TiO}_{2}$ and $\mathrm{HA}-\mathrm{ZrO}_{2}$ biocomposite coatings, a new procedure is used which is different from previous procedures found in the literature $[3,24,28-30]$. For this goal, a merged electrodeposition method is designed, merging electrochemi$\mathrm{cal}$ and electrophoretic deposition. Herein, the main aim was to investigate the possibility of coating $\mathrm{HA}-\mathrm{TiO}_{2}$ and
$\mathrm{HA}-\mathrm{ZrO}_{2}$ composite coatings using merged solutions and investigating the effect of $\mathrm{TiO}_{2}$ and $\mathrm{ZrO}_{2}$ nanoparticle addition on hydroxyapatite matrix characteristics. According to the available literature: (1) different additives to the hydroxyapatite structure have different effects on HA structure; and (2) additive content has effects on the HA, too. Therefore, in this study two different compositing agents (titania and zirconia) were used to investigate the difference between the compositing agent; and each one was used at two concentrations to evaluate the effect of additive content, too. The solution was prepared by merging calcium-phosphor saline solution and nanoparticle suspension. The schematic illustration of the electrodeposition procedure is represented in Fig. 1. To the best of our knowledge, this is the first study using this procedure and comparing the $\mathrm{HA}-\mathrm{TiO}_{2}$ and $\mathrm{HA}-\mathrm{ZrO}_{2}$ composite coatings. Different analyses were used to understand the effects of titania and zirconia nanoparticles on HA matrix properties and differences between coatings.

\section{Experimental procedure}

\subsection{Materials}

316 stainless steel sheets were used as cathode and anode. $\mathrm{Ca}\left(\mathrm{NO}_{3}\right)_{2}$ and $\mathrm{NH}_{4} \mathrm{H}_{2} \mathrm{PO}_{4}$ were used to prepare Calcium-Phosphate solution, $\mathrm{NaNO}_{3}$ was used to adjust ionic strength of the solution and $\mathrm{HNO}_{3}-\mathrm{NaOH}$ were used to adjust the $\mathrm{pH}$ (Merck CO.). As compositing agent, titania $\left(\mathrm{TiO}_{2}\right.$ Anatase grade- typical size of $15 \mathrm{~nm}$ Tecnan CO., Spain) and zirconia nanoparticles $\left(\mathrm{ZrO}_{2}\right.$ Tetragonal grade- typical size of $15 \mathrm{~nm}$ Tecnan CO., Spain) were used as received. Materials used to prepare SBF solution were bought from Merck CO. and used as received.

\subsection{Coating procedure}

Stainless steel sheets $(50 \mathrm{~mm} \times 20 \mathrm{~mm} \times 3 \mathrm{~mm}$ ) were gritted with $\mathrm{SiC}$ papers ranging from $\mathrm{P} 320$ to $\mathrm{P} 2000$ grit, washed with distilled water and etched in $0.5 \mathrm{M} \mathrm{HCL}-\mathrm{HNO}_{3}$ for $30 \mathrm{~s}$ to increased coating adhesion to the substrate and decrease HA grains size. Finally, substrate was degreased in acetone for 10 min using sonic bath and rinsed in distilled water. Having a stable merged solution of calcium-phosphate-titania and calcium-phosphate-zirconia for electrodeposition, acidic pH equal to 4.2 was chosen.

In this research, hydroxyapatite saturated solution was prepared as follows: $20 \mathrm{mM} \mathrm{Ca}\left(\mathrm{NO}_{3}\right)_{2}$ was dissolved in distilled water and stirred, then, $12 \mathrm{mM} \mathrm{NH}_{4} \mathrm{H}_{2} \mathrm{PO}_{4}$ was added, $0.01 \mathrm{M} \mathrm{NaNO}_{3}$ was added to adjust ionic strength of solution and $\mathrm{pH}$ was adjusted 4.2 by diluted $\mathrm{HNO}_{3}$ and $\mathrm{NaOH}$. As compositing agent, titania and zirconia nanoparticles 


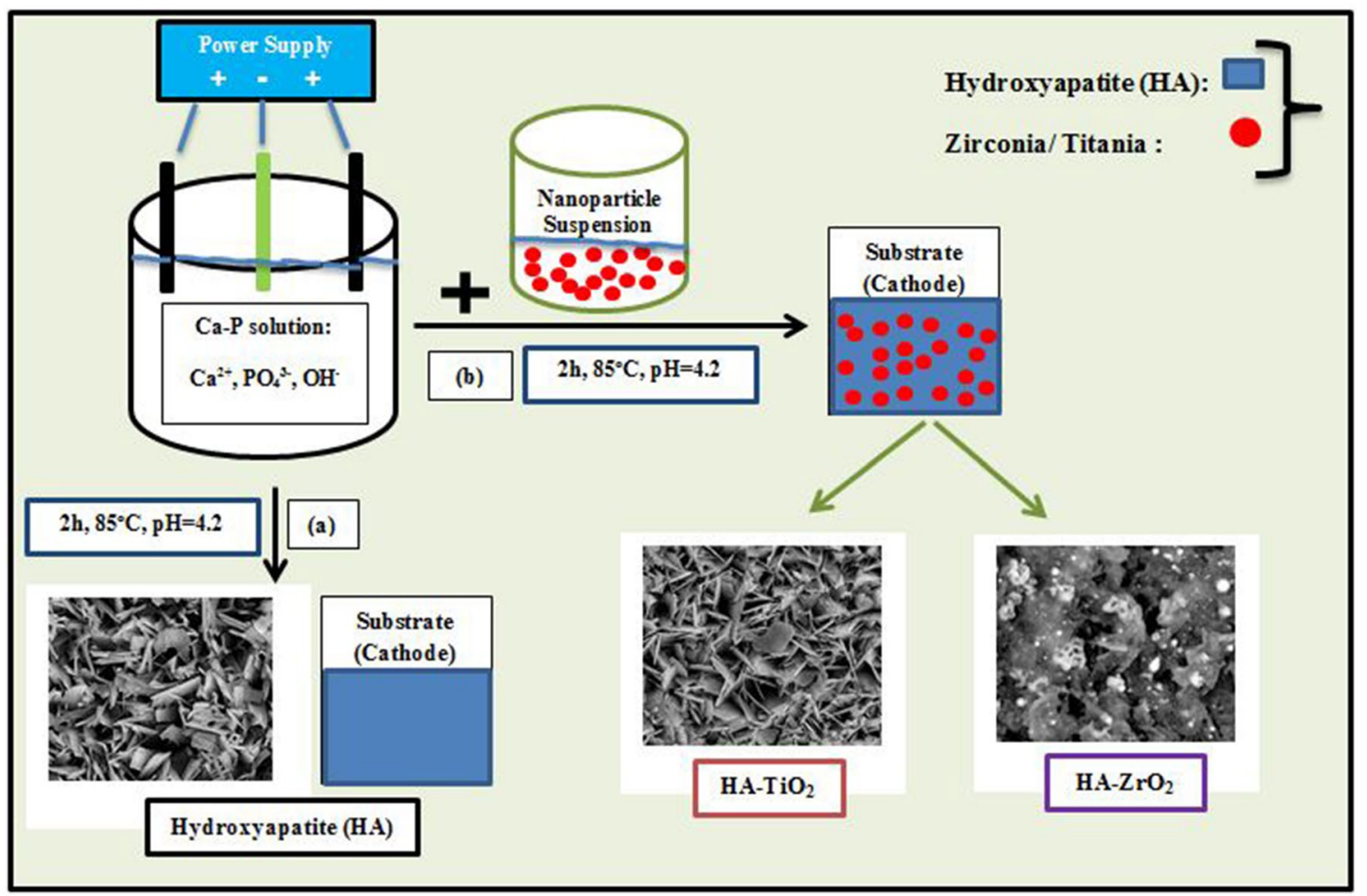

Fig. 1 Schematic of the electrodeposition process; a electrodpeosition of hydroxyapatite (HA) using Ca-P solution, b adding nanoparticle suspension to the $\mathrm{Ca}-\mathrm{P}$ solution and electrodpeosition of composite coating

Table 1 Concentration of different reagents in $\mathrm{HA}, \mathrm{HT}$ and $\mathrm{HZ}$ solutions

\begin{tabular}{lllll}
\hline & $\mathrm{Ca}(\mathrm{mM} / \mathrm{l})$ & $\mathrm{Ti}(\mathrm{mM} / \mathrm{l})$ & $\mathrm{Zr}(\mathrm{mM} / \mathrm{l})$ & $(\mathrm{Ti}-\mathrm{Zr}) / \mathrm{Ca}$ \\
\hline $\mathrm{HA}$ & 20 & 0 & 0 & 0 \\
$\mathrm{HT}_{1}$ & 20 & 3 & 0 & 0.15 \\
$\mathrm{HT}_{2}$ & 20 & 6 & 0 & 0.30 \\
$\mathrm{HZ}_{1}$ & 20 & 0 & 3 & 0.15 \\
$\mathrm{HZ}$ & 20 & 0 & 6 & 0.30 \\
\hline
\end{tabular}

were used. Hydroxyapatite-titania samples were named HT coatings and hydroxyapatite-zirconia samples were named $\mathrm{HZ}$ coatings. In order to have rational molar ratios of compositing agent to matrix, two different concentrations of titania and zirconia were used, $3 \mathrm{mM}$ and $6 \mathrm{mM}$. Solutions for different coatings are represented in Table 1. The $\mathrm{HA}-\mathrm{TiO}_{2}(\mathrm{HT})$ solutions were prepared merging $\mathrm{HA}$ solution and titania suspension as follows; first, HA solution was prepared as described previously, then, titania aqueous suspension was prepared and gently added to $\mathrm{Ca}-\mathrm{P}$ solution. To make stable aqueous suspension, the $\mathrm{pH}$ of distilled water was adjusted 4.2 (similar to the $\mathrm{pH}$ of HA solution) and titania nanoparticles were added, ultrasonic dispersion done for 30 min and magnetic stirring done for $20 \mathrm{~min}$. Now, the titania suspension was gently added to the $\mathrm{Ca}-\mathrm{P}$ solution to prepare $\mathrm{HA}-\mathrm{TiO}_{2}$ solution. Finally, the merged solution stirred for $15 \mathrm{~min}$ to have stable and uniform solution. $\mathrm{HA}-\mathrm{ZrO}_{2}$ solutions were prepared the same as $\mathrm{HA}-\mathrm{TiO}_{2}$ solutions. Electrodeposition was carried out in a three electrode cell, 316 SS as cathode and two 316 SS sheets as anode. Deposition conditions for pure $\mathrm{HA}, \mathrm{HT}$ and $\mathrm{HZ}$ coatings was similar. Deposition was done in constant current density mode, the $\mathrm{pH}$ of the solutions was adjusted to 4.2 , at $85^{\circ} \mathrm{C}\left(\mathrm{T}=85 \pm 5^{\circ} \mathrm{C}\right)$ for $2 \mathrm{~h}$. Magnetic stirring at $200 \mathrm{rpm}$ was used to have uniform concentration and temperature condition during deposition.

\subsection{Characterization of coatings}

The thickness of coatings was measured using a Dual Scope MP40, Fischer, Switzerland thickness meter. The zeta potential of the particles in the suspension was measured using Zetasizer ZEN 3600 (Malvern, UK). X-ray diffraction (XRD: X'pert Philips pw 3040/60,Cu Ka 1.54056 A) was used to determine the $\mathrm{Ca}-\mathrm{P}$ phases synthesized in the coating process. Degree of the crystallinty $(\mathrm{Xc})$ of HA coatings was evaluated according to the Eq. (1) [31].

$\mathrm{Xc}=(0.24 / \beta \mathrm{m})^{3}$

where $\beta \mathrm{m}$ is the corrected full width of the peak (plane) at half of the maximum intensity (FWHM) [31, 32]. The 
fourier-transform infrared (FTIR) spectra of samples were collected over the range of $400-4000 \mathrm{~cm}^{-1}$ using (EQUINOX 55 Germany) to determine absorbed functional groups in $\mathrm{Ca}-\mathrm{P}$ deposited film. The deposited coatings were scrapped from the substrate and used in XRD and FTIR analyses. The surface morphology, cross section topography and chemical composition were studied using FESEM (MIRA3, TE-SCAN FESEM) equipted with energy dispersive spectroscopy (EDS: EDS is a semi-quantitative test). The evaluation of electrochemical behavior of coatings was done with polarization test using a 273 A potentiostat/galvanostat utensil. Polarization tests were carried out at the same mode for the bare substrate, HA coated sample and composite coated samples. Polarization tests were carried out at $\mathrm{T}=37^{\circ} \mathrm{C}$, in SBF solution, using a common three electrode cell; using saturated calomel electrode (SCE) as reference electrode, 316 SS as counter and coated samples as working electrode. Polarization measurements were done after the attainment of steady OCP conditions (Before applying on the system in each test, the samples were immersed approximately $15 \mathrm{~min}$ in SBF to establish the open circuit potential.). Potential varied $-300 \mathrm{mV}$ to $+300 \mathrm{mV}$ relative to OCP and scan rate was $1 \mathrm{mV} / \mathrm{S}$. Open porosity ratio of the coating was evaluated using the mixed potential theory. The mixed potential reached by the couple is [33]:

$E_{m}=E_{c o r r(A)}+b_{A} \log \left(S_{C} / S_{A}\right)$,

where $E_{m}$ is the mixed potential of the coated substrate, $E_{\text {corr(A) }}$ is the corrosion potential of the substrate (anodic metal), $b_{A}$ is the anodic Tafel slope of the substrate, and $\mathrm{S}_{C} / \mathrm{S}_{A}$ is the surface ratio [33]. The $\mathrm{S}_{A} / \mathrm{S}_{C}$ ratio defines the open porosity value. The bioactivity of the coatings was examined using immersion test in SBF solution and following FESEM observation. All the samples were soaked in SBF solution for 30 days, $\mathrm{T}=37^{\circ} \mathrm{C}$ and fixed position. After 30 days, samples were brought out and washed gently with distilled water and dried in atmosphere. It should be stated that SBF was made according to the Kokubo's order [34].

\section{Results and discussion}

\subsection{Thickness of coating and Zeta potential of suspensions}

The thickness of a coating has critical role on the quality and performance of the coating [35]. The thickness of an electrodeposited coating is a result of different parameters such as voltage, current density, electrodeposition time, electrodeposition temperature and electrolyte additives [36]. Herein, as mentioned in coating procedure, two parameters are changing: (1) nanoparticle type, (2) nanoparticle content. The thicknesses of different coatings were measured at five points and the mean value is reported in Table 2 . Regarding Table 2, composite coatings are thinner than pure hydroxyapatite coating and increasing nanoparticle concentration in the solution results in thinner coating. Maybe, this behavior is due to the nanoparticles deposition. Firstly, the diffusion rate of ions is a critical factor which affects coating thickness [37, 38]. In the case of $\mathrm{HA}$ solution, $\mathrm{Ca}^{2+}, \mathrm{OH}^{-}$and $\mathrm{PO}_{4}{ }^{3-}$ ions can reach the substrate with more diffusion rate than $\mathrm{HT}$ and $\mathrm{HZ}$ solutions, owing to nanoparticles ban and stop ions motion [38]. Secondly, nanoparticles adhesion to substrate inserts pressure on HA matrix and this results in thickness decreasing [39]. Therefore, concerning the coating parameters such as time, temperature, voltage and additives, we assume that the coating thickness is a function of the solution ingredients, adding titania and zirconia nanoparticles to the $\mathrm{Ca}-\mathrm{P}$ solution resulted in thinner coatings. The zeta potentials of titania $(6 \mathrm{mM})$ and zirconia $(6 \mathrm{mM})$ nanoparticle suspensions were +36 and $+33 \mathrm{mV}$, respectively. The positive charge of the particles results in the adsorption of particles to the cathode and this results to the simultaneous deposition of hydroxyapatite matrix and titania (zirconia) particles on cathode surface [21]. Complete results of coating thicknesses and suspension zeta potentials are reported in Table 2.

\subsection{Phase composition}

XRD is done to analyze the phase composition of the coatings and the obtained patterns are illustrated in the Fig. 2. The presence of hydroxyapatite peaks at $2 \theta \sim 26^{\circ}$, $32^{\circ}, 33^{\circ}, 49^{\circ}$ relating to $(002),(211),(112),(213),(004)$ crystallographic planes indicates that $\mathrm{HA}$ is formed using this electrodeposition condition [3, 16, 37, 40]. Strong peak at $2 \theta \sim 26^{\circ}((002)$ plane) suggesting the preferential growth of HA crystals perpendicular to electrode surface usually occurs in electrochemical deposition [31]. Among different calcium-phosphate phases, octacalcium phosphate $\left(\mathrm{OCP}=\mathrm{Ca}_{8} \mathrm{H}_{2}\left(\mathrm{PO}_{4}\right)_{6} \cdot 5 \mathrm{H}_{2} \mathrm{O}\right)$ synthesizes from acidic solutions because of $\mathrm{H}^{+}$ions saturation, therefore It's

Table 2 Zeta potentials of HT and HZ suspensions and thicknesses of the coatings

\begin{tabular}{llll}
\hline & Zeta $(\mathrm{mV})$ & Thickness $(\mu \mathrm{m})$ & $\mathrm{SD}$ \\
\hline $\mathrm{HA}$ & - & 5.5 & 0.23 \\
$\mathrm{HT}_{1}$ & +35 & 4.8 & 0.19 \\
$\mathrm{HT}_{2}$ & +36 & 4.6 & 0.21 \\
$\mathrm{HZ}_{1}$ & +34 & 4.7 & 0.25 \\
$\mathrm{HZ}_{2}$ & +33 & 4.4 & 0.21 \\
\hline
\end{tabular}




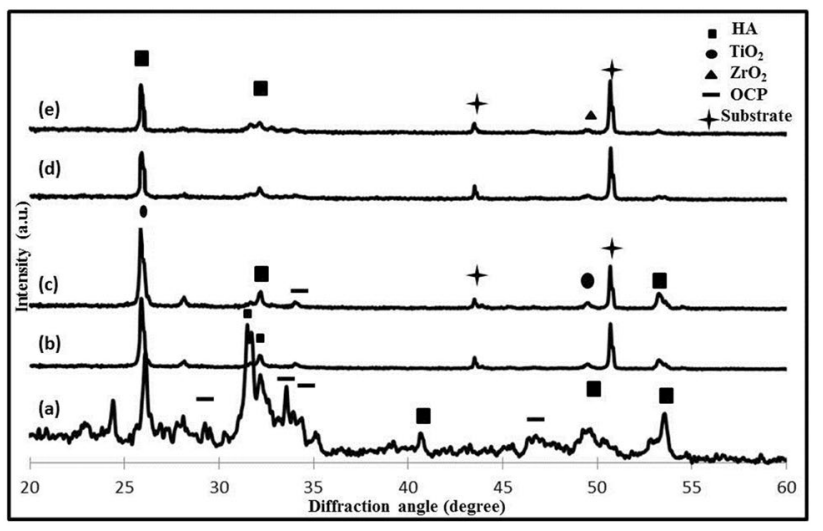

Fig. 2 XRD diagrams of a HA, b HT $1, \mathbf{c H T}_{2}, \mathbf{d ~ H Z}, \mathrm{HZ}_{1}, \mathbf{H Z}$ coatings

predictable to have both HA and OCP while using acidic solution $[40,41]$. In Fig. 2a, the low intensity peaks of octacalcium phosphate are observed which means OCP is synthesized as well as HA. Octacalcium phosphate peaks are visible at $2 \theta \sim 23^{\circ}$ and $29^{\circ}$ corresponding to (111) and (330) planes $[37,40]$. Regarding the precursor model proposed by Brown [42], OCP is the precursor phase for hydroxyapatite, at high deposition temperature (for example $80^{\circ} \mathrm{C}$ ) and through the time of deposition, octacalcium phosphate gradually transforms to hydroxyapatite [37, 41]. The co-existence of HA and OCP prepares two phase Calcium-Phosphate coatings which is intended when higher bioactivity is required $[6,40,43]$. Moreover, in the XRD patterns of composite coatings, additional peaks are visible.

The XRD diagram of HT coatings have peaks at $2 \theta \sim 25.5^{\circ}$ and $28^{\circ}$ which are related to $(101)$ and $(-111)$ planes of titania, respectively [44], this indicates that HA and $\mathrm{TiO}_{2}$ are successfully codeposited. Comparing $\mathrm{HT}_{1}$ and $\mathrm{HT}_{2}$ coatings in Fig. $2 \mathrm{~b}, \mathrm{c}$ suggests that titania content does not change the diagram and intensity or existence of the peaks are not changed. Two clear differences between XRD diagrams of hydroxyapatite and HT coatings are: (1) OCP peaks are disappeared in HT coatings, (2) hydroxyapatite peak at $32^{\circ}$ is disappeared which means that this growth plane is not preferential growth for HT coatings. XRD diagram of $\mathrm{HZ}$ coatings in Fig. $2 \mathrm{~d}$, e has similar condition to $\mathrm{HT}$ coatings, new peaks are visible at $2 \theta \sim 28^{\circ}$ and $59^{\circ}$ which are related to $\mathrm{ZrO}_{2}$ composite reagent [45], that shows the codeposition of $\mathrm{HA}$ and $\mathrm{ZrO}_{2}$ compounds. XRD diagrams of $\mathrm{HZ}_{1}$ and $\mathrm{HZ}_{2}$ coatings are very similar. This means that zirconia content does not change the XRD pattern. Furthermore, Two clear differences between XRD diagrams of hydroxyapatite and $\mathrm{HZ}$ coatings are: (1) OCP peaks are disappeared in $\mathrm{HZ}$ coatings, (2) hydroxyapatite peak at $32^{\circ}$ is disappeared which means that this growth plane is not preferential growth for $\mathrm{HZ}$ coatings. Regarding the Sect. 2.1, using rational concentration of titania and
Table 3 FWHM and $\mathrm{Xc}$ of $\mathrm{HA}$, $\mathrm{HT}$ and $\mathrm{HZ}$ coatings

\begin{tabular}{lllll}
\hline & $2 \theta$ & $\mathrm{Ka}$ & $\mathrm{b}_{\mathrm{m}}$ & $\mathrm{X}_{\mathrm{c}}$ \\
\hline $\mathrm{HA}$ & 26 & 0.24 & 0.26 & 0.80 \\
$\mathrm{HT}_{1}$ & 26 & 0.24 & 0.25 & 0.84 \\
$\mathrm{HT}_{2}$ & 26 & 0.24 & 0.25 & 0.85 \\
$\mathrm{HZ}_{1}$ & 26 & 0.24 & 0.25 & 0.86 \\
$\mathrm{HZ}_{2}$ & 26 & 0.24 & 0.25 & 0.86 \\
\hline
\end{tabular}

zirconia to prepare the solutions for composite coatings, the absence or weak peaks for crystalline $\mathrm{TiO}_{2}$ and $\mathrm{ZrO}_{2}$ in $X R D$ diagrams suggest that nanoparticles have amorphous structure $[16,29]$. As stated for $\mathrm{HT}$ and $\mathrm{HZ}$ coatings, OCP peaks are disappeared. Referring to precursor model proposed by Brown [42], authors suggest two mechanisms: (1) nanoparticles serve as nucleation sites for HA matrix and this reduces the precursor effect of octacalcium phosphate, (2) nanoparticles serve as catalyst phase to increase OCP to HA transition kinetics. Another useful parameter that can be extracted from XRD diagrams, is the degree of crystallinity $\left(X_{c}\right)$ of $H A$ according to the Eq. (1) [31]:

$\mathrm{Xc}=(0.24 / \beta \mathrm{m})^{3}$

where $\beta \mathrm{m}$ is the corrected [31] full width of the peak (plane) at half of the maximum intensity (FWHM) [31, 32]. $X c$ results are expressed in Table 3 . It is clear that different coatings of this study, specially pure HA, have really appreciable and higher $\mathrm{Xc}$ related to the previous studies $[3,31,32]$. Higher Xc shows more crystalline HA character, more biocompatibility and natural bone behavior $[3,31$, 32]. Hydroxyapatite deposition on the substrate surface occurs with heterogeneous nucleation mechanism which is mainly depended on the surface parameters $[14,46]$. Nanoparticles have really high effective surface area and this makes favorable positions for heterogeneous nucleation; so increased crystallinity of hydroxyapatite is maybe occurred by adding nanoparticles.

\subsection{FTIR analysis}

Figure 3 illustrates the FTIR spectra recorded in the case of $\mathrm{HA}, \mathrm{HT}_{2}$ and $\mathrm{HZ}_{2}$ films deposited on the stainless steel substrate. When analyzing hydroxyapatite structure, the presence of $\mathrm{OH}^{-}$and $\mathrm{PO}_{4}{ }^{3-}$ ions that are characterized for hydroxyapatite in FTIR spectra can prove the formation of hydroxyapatite. In HA structure, there are four vibration modes $\left(\mathrm{v}_{1}-\mathrm{v}_{4}\right)$ for $\mathrm{P}-\mathrm{O}$ bands in the $\mathrm{PO}_{4}{ }^{3-}$ ion. The $v_{4}$ (asymmetric bending) bands at $520-660 \mathrm{~cm}^{-1}$, the $v_{2}$ (bending band) at $437 \mathrm{~cm}^{-1}$ and $471 \mathrm{~cm}^{-1}$ as well as the $v_{1}$ (symmetric stretching) and $v_{3}$ (asymmetric stretching) spectral bands positioned at $900-1200 \mathrm{~cm}^{-1}$, are useful in identifying the structure of hydroxyapatite $[32,37,41,47]$. A libration band at $\sim 630 \mathrm{~cm}^{-1}$ is the typical of structural 


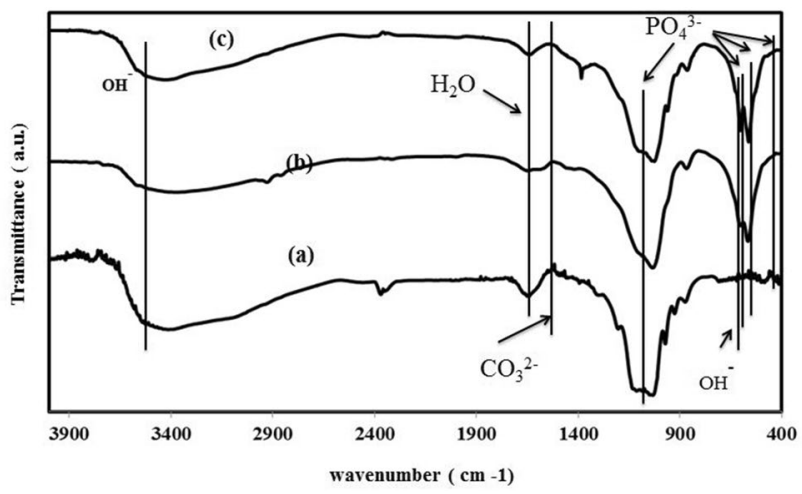

Fig. 3 FTIR spectra of a HA, b HT ${ }_{2}, \mathbf{c ~ H Z} 2$ coatings

$\mathrm{OH}^{-}$in $\mathrm{HA}$ structure [32]. On the one hand, broad band at $3457 \mathrm{~cm}^{-1}$ can be assigned to the $\mathrm{OH}^{-}$stretching vibration of HA coating [47], on the other hand, this band is also at the position of the stretching mode of adsorbed water $[16,47]$. Furthermore, the vibration at $1635 \mathrm{~cm}^{-1}$ is attributed to the stretching peak of adsorbed water [16, 32 ,37]. Finally, it should be taken into account that XRD and FTIR analyses show that HA is synthesized in pure and composite coatings.

\subsection{Morphology and chemical composition}

Figure $4 a-d$ shows the FESEM observations of hydroxyapatite coating electrodeposited using Ca-P solution. It can be understood that hydroxyapatite has continuous and uniform character that can protect the substrate and ban the contact between substrate and surrounding environment. Hydroxyapatite plates are observed and surface is covered with packed plates that is similar to $\mathrm{Ca}-\mathrm{P}$ electrodeposited coatings formed before by Shirkhanzadeh and Eliaz et al. [37, 41]. The growth of the HA perpendicular to the surface of the substrate is evidently observed in Fig. 4a [16]. Regarding Fig. 4a plate size is in the range of 2-4 $\mu \mathrm{m}$ which is smaller and thinner than previous reports $[37,41]$. Smaller dimensions results more surface
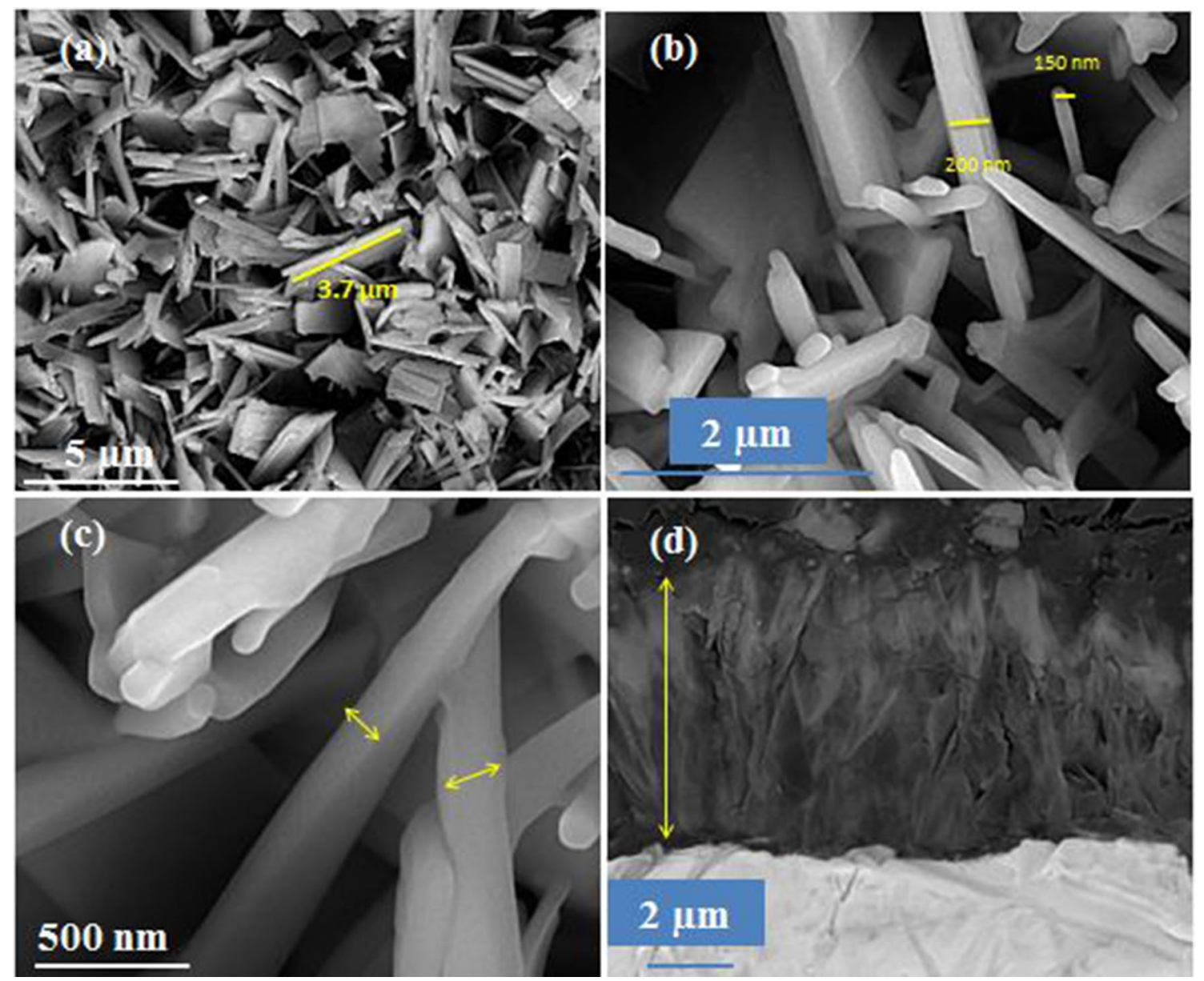

Fig. 4 FESEM images of hydroxyapatite; a HA morphology and microstructure, b, c HA at higher magnification (arrows showing width and height of $\mathrm{HA}$ plates), $\mathbf{d}$ cross section of $\mathrm{HA}$ 
area, therefore, more area will be in contact with surrounding solution such as simulated body fluid $[27,48]$ and this property will be preferable when bioactivity is the main concern. By increasing the magnification in Fig. $4 b$, c, the compact and crossed planes of hydroxyapatite are clear. Furthermore, the width and height of HA plates can be estimated under $100 \mathrm{~nm}$ and $200 \mathrm{~nm}$, respectively. The mean $\mathrm{Ca} / \mathrm{P}$ molar ratio (EDS) in Fig. $4 \mathrm{~b}$ was 1.47. Although the $\mathrm{Ca} / \mathrm{P}=1.47$ is not stoichiometric value for hydroxyapatite, natural bone is not stoichiometric too [49]. Figure $4 d$ shows that cross-section of HA coating is uniform, with an estimated thickness of approximately $5.5 \mu \mathrm{m}$ (vertical line) and the coating seems compact and free of cracks. The morphologies obtained using $\mathrm{HT}_{1}$ and $\mathrm{HT}_{2}$ solutions are shown in Fig. 5a-e and Fig. 6a, e, respectively. HT coatings show a bit different morphology rather HA coating which is due to the nanoparticle addition. By adding titania to the solution, morphology is more homogenous and ordered perpendicular to the surface, plate size is decreased and more compact structure is formed. In $\mathrm{HT}_{1}$ coating, Fig. $5 \mathrm{a}, \mathrm{e}, \mathrm{HA}$ plate dimension is nearly $0.5-2 \mu \mathrm{m}$ which is smaller than plate dimension in HA coating. This change is occurred because of the nanoparticles presence. Firstly, deposited particles prepare more nucleation sites for $\mathrm{HA}$ matrix nucleation [46], then, nanoparticles deposit at HA plates and stop plate growth. By increasing magnification in Fig. 5b, c some new changes are visible. For example, codeposited nanoparticles which are mainly below $20 \mathrm{~nm}$ are clearly seen, and nanoparticles are deposited on HA planes and pores, especially on the edge of the planes as preferential sites (rectangle marks). EDS results reveal that the $\mathrm{Ca} / \mathrm{P}$ molar ratio and the wt $\%$ of titanium in the $\mathrm{HT}_{1}$ coating are 1.61 and 4.21 , respectively. According to Fig. 6a, e, increasing $\mathrm{TiO}_{2}$ concentration in $\mathrm{HT}_{2}$ coating toughens up the trend observed and discussed for $\mathrm{HT}_{1}$ coating. As visible, hydroxyapatite plates are more packed and smaller in dimension (the length of plates is below $1 \mu \mathrm{m}$ in Fig. 6a), The porosity radius is reduced (comparing Figs. 5b, 6b) and more titania nanoparticles are deposited in the coating. The $\mathrm{Ca} / \mathrm{P}$ molar ratio and the $\mathrm{wt} \%$ of titanium in the $\mathrm{HT}_{2}$ coating are 1.53 and 7.5 , respectively. To investigate the distribution of $\mathrm{TiO}_{2}$ nanoparticles in $\mathrm{HT}_{1}$ and $\mathrm{HT}_{2}$ coatings, EDS mapping is done and the results are presented in Figs. $5 \mathrm{~d}$ and $6 \mathrm{~d}$, respectively. It's clear that $\mathrm{Ti}$ (green dots) is homogenously distributed on the entire surface of both coatings. The homogenous distribution of $\mathrm{TiO}_{2}$ may mean that the effects of titania addition are visible all over the surface, which is a good behavior.

Figures $5 e$ and 6e show cross-sectional topography of $\mathrm{HT}_{1}$ and $\mathrm{HT}_{2}$ coatings, respectively. The deposited coatings are adhered to the substrate completely and no crack is visible in the topography. The thicknesses of $\mathrm{HT}_{1}$ and
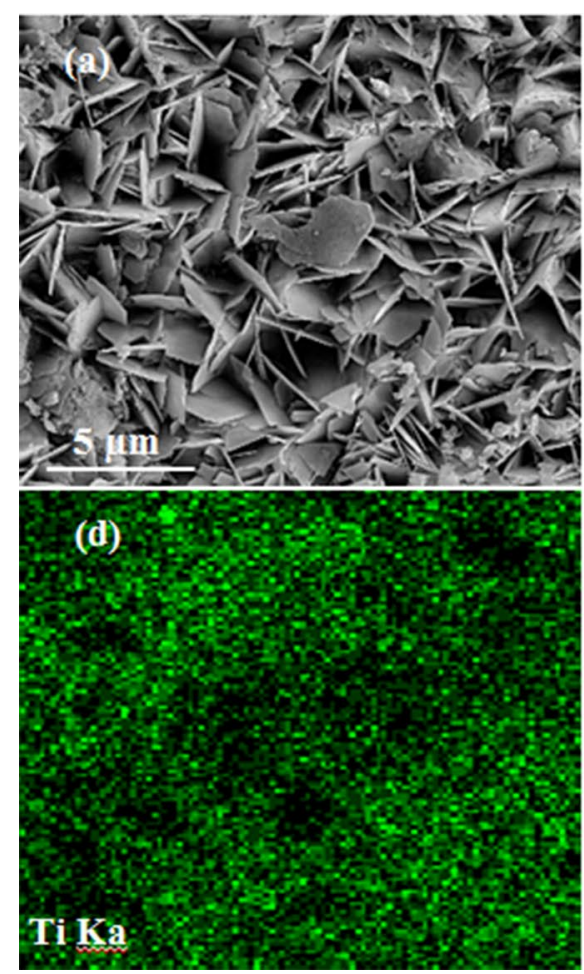
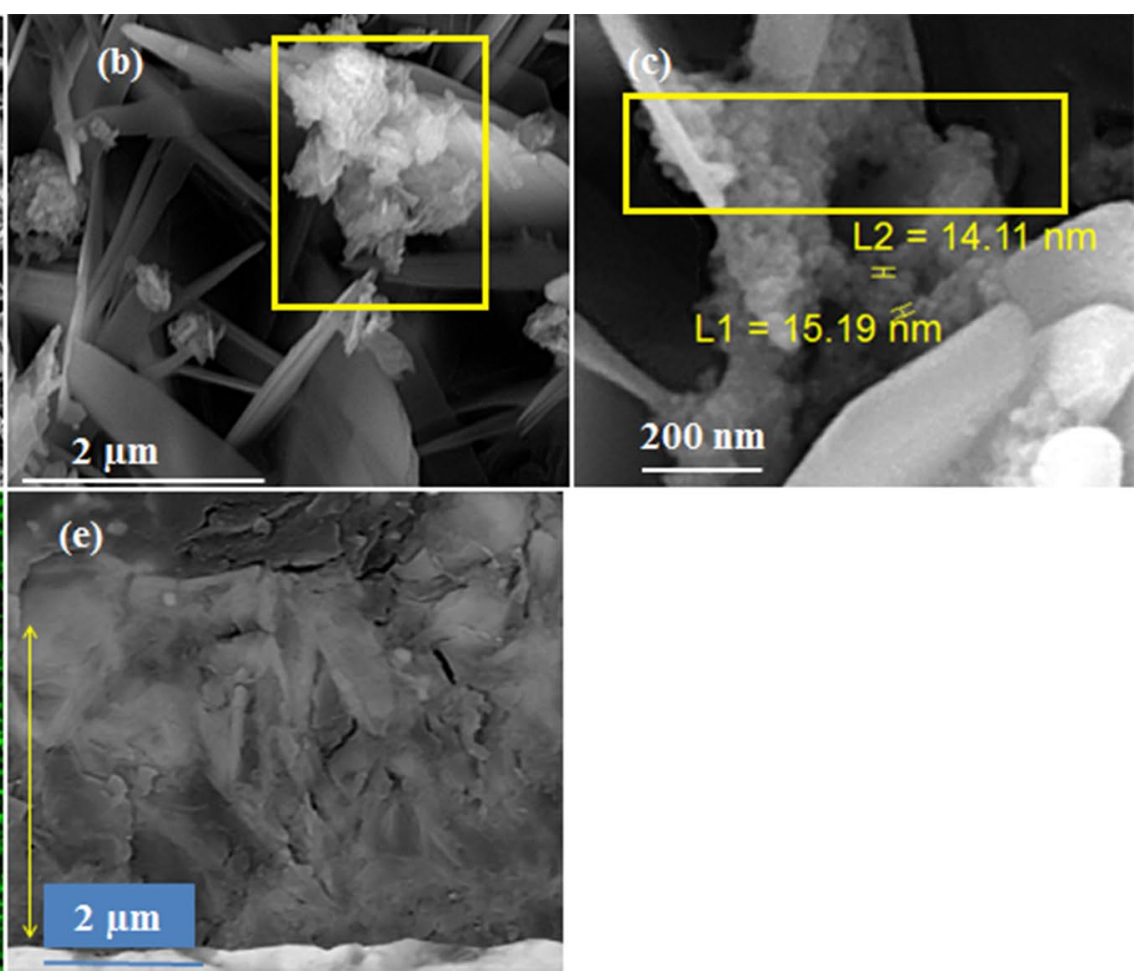

Fig. 5 FESEM images of $\mathrm{HT}_{1}$ coating; a $\mathrm{HT}_{1}$ coating, b, $\mathbf{c} \mathrm{HT}_{1}$ at higher magnification, rectangle indicates nanoparticle deposition, d EDS mapping of titanium, e cross section of $\mathrm{HT}_{1}$ coating 

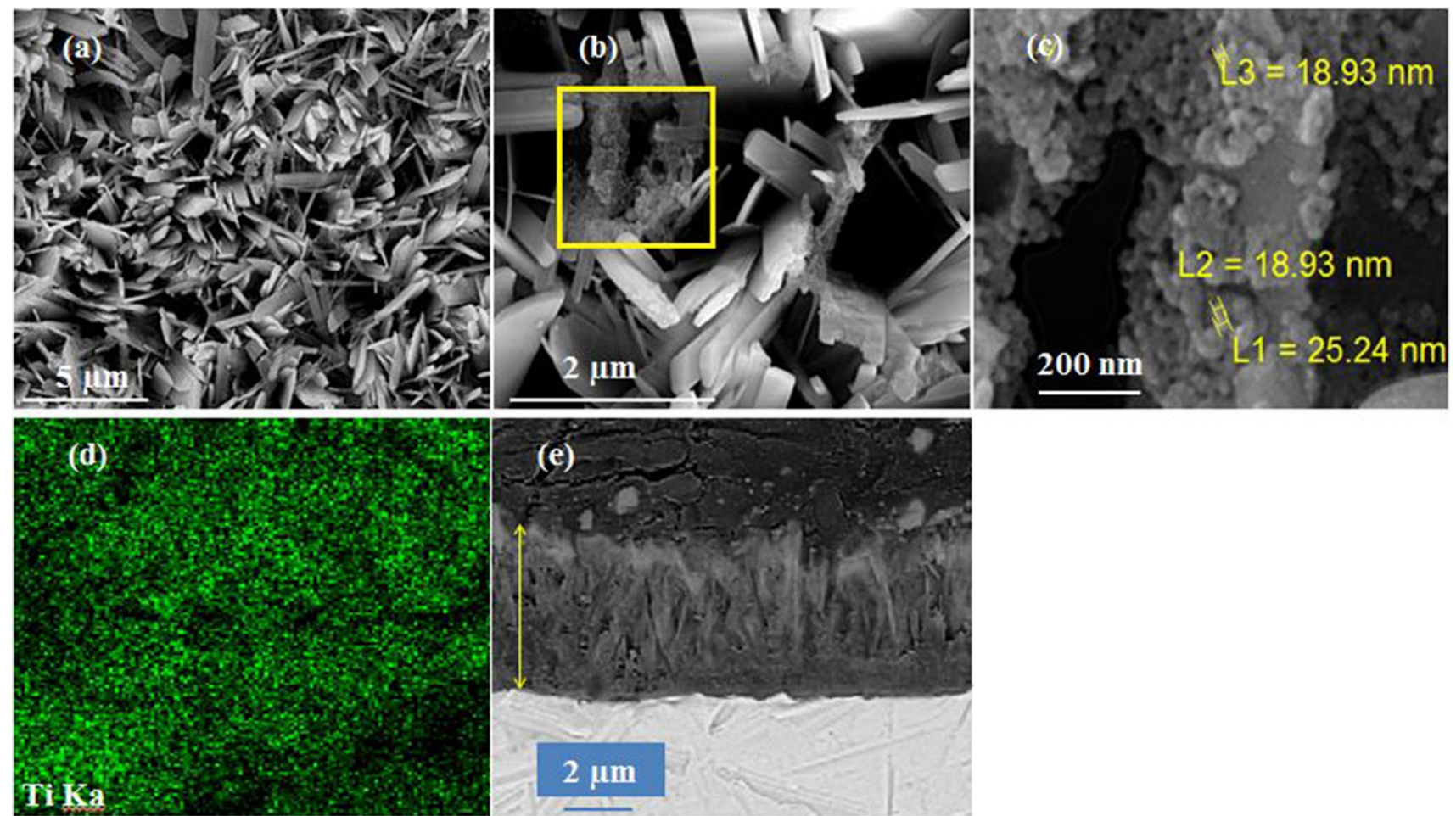

Fig. 6 FESEM images of $\mathrm{HT}_{2}$ coating; a $\mathrm{HT}_{2}$ coating, $\mathbf{b}, \mathbf{c} \mathrm{HT}_{2}$ at higher magnification showing titania particles deposition (rectangle) and hydroxyapatite plates, d EDS mapping of titanium, e cross section of the $\mathrm{HT}_{2}$ coating

$\mathrm{HT}_{2}$ coatings are nearly the same as the measured ones in Table 2. FESEM images of $\mathrm{HZ}_{1}$ and $\mathrm{HZ}_{2}$ coatings are shown in Figs. $7 \mathrm{a}-\mathrm{e}$ and $8 \mathrm{a}-\mathrm{e}$, respectively. As visible, in $\mathrm{HZ}$ coatings hydroxyapatite structure is vigorously changed and film forming structure is visible [50].

Figure 7 a shows that surface morphology of $\mathrm{HZ}_{1}$ coating consists of hydroxyapatite film, sub-micron HA plates and zirconia particles. By increasing magnification in Fig. 7b; hydroxyapatite nano-rods are visible which was not observed for HA and HT coatings, zirconia nanoparticles deposited on HA structure are visible (marked with rectangle) and more compact morphology structure than $\mathrm{HA}$ and $\mathrm{HT}$ coatings is visible. Figure $7 \mathrm{c}$ confirms than zirconia nanoparticles are successfully deposited. Figure 8a, $\mathrm{b}$ shows that the pure hydroxyapatite morphology which was plate structure is completely changed and film forming is the dominant growth mechanism and surface is covered with HA film, no plate or rod is visible. In Fig. 8b, zirconia nanoparticles deposited on HA film are visible (marked with rectangle), continues HA film is visible and no porosity is observed. Figure $8 \mathrm{c}$ confirms than zirconia nanoparticles are successfully deposited. Comparing surface morphologies of $\mathrm{HZ}_{1}$ and $\mathrm{HZ}_{2}$ coatings shows that increasing zirconia concentration in the solution results to more deposition of zirconia particles in the coating and this observation is in accordance with EDS results as follows. Furthermore, Figs. 7a and 8a show micro $\mathrm{ZrO}_{2}$ particles, meaning that nanoparticles agglomeration has occurred, maybe, because of high deposition temperature [17]. To evaluate the distribution pattern of $\mathrm{ZrO}_{2}$ particles in the $\mathrm{HZ}$ composite coatings, EDS mapping is done. The EDS maps of $\mathrm{HZ}_{1}$ and $\mathrm{HZ}_{2}$ coatings are presented in Fig. $7 \mathrm{~d}$ and $8 \mathrm{~d}$, respectively. The existence of targeted element ( $\mathrm{Zr}$ ) was marked by colored (red) dots. It's clear that $\mathrm{Zr}$ is homogenously distributed on the coatings surface and well covers the area. There are several regions that The $\mathrm{Zr}$ map is apparently more concentrated there, this can be ascribed to the agglomeration of Zirconia nanoparticles. Cross-sectional topographies of $\mathrm{HZ}_{1}$ and $\mathrm{HZ}_{2}$ coatings are shown in Figs. $7 \mathrm{e}$ and $8 \mathrm{e}$, respectively. There is a robust coating structure and complete adhesion between the deposited coating and the underlying substrate. This indicates that the coating is really compacted and tightly adhered to the substrate. Finally, it is known that bone is composed of nanocrystals of apatite in collagen matrix, therefore, bioactivity and osteoconductivity of coating could be further improved if coating materials were closer to bone mineral in crystal structure, size and morphology [51]. As seen, in this research composite coatings have smaller apatite size than pure hydroxyapatite and contain nanoparticles which can improve bioactivity and osteoconductivity of the coating. Complete EDS analysis 

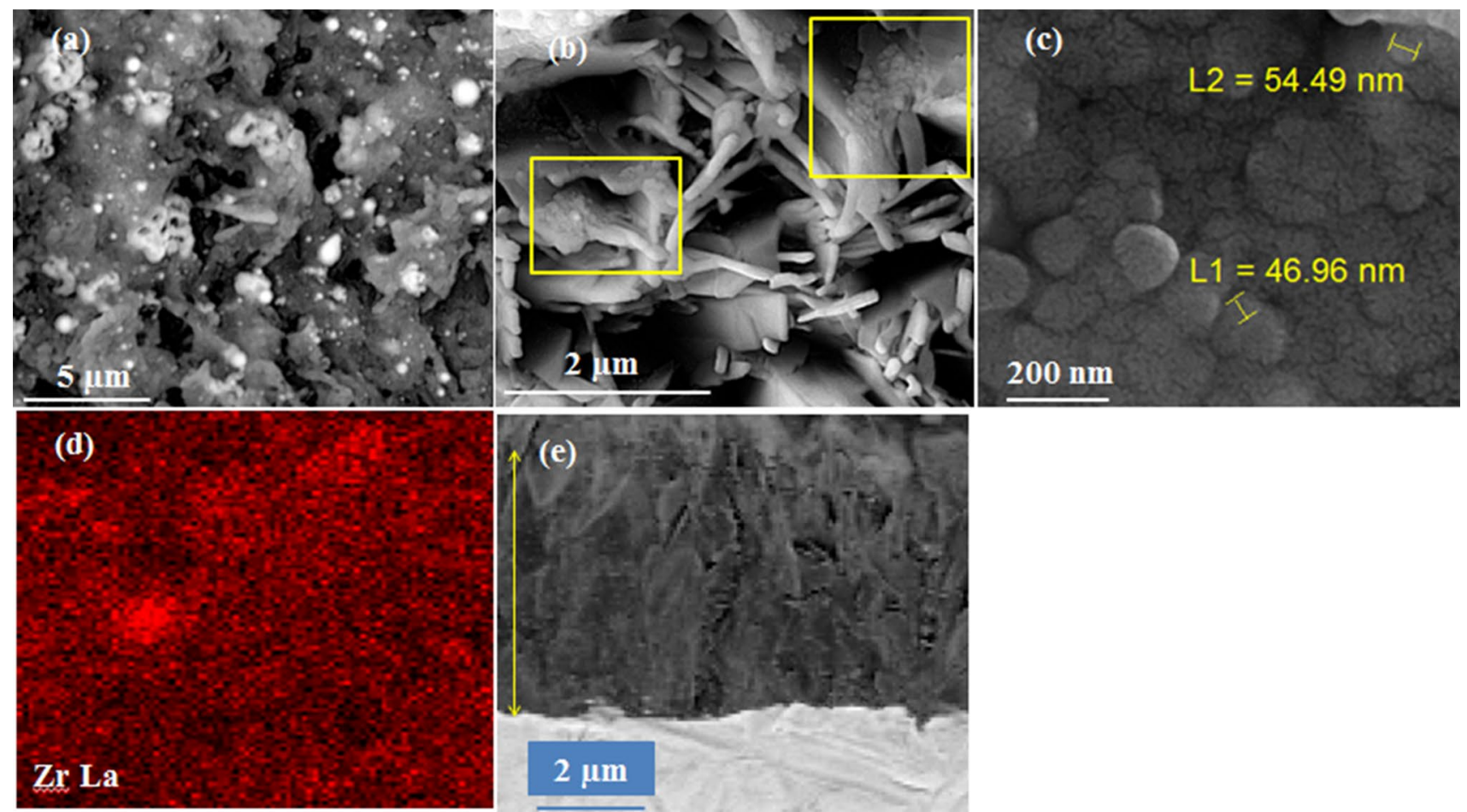

Fig. 7 FESEM images of $\mathrm{HZ}_{1}$ coating; $\mathbf{a} \mathrm{HZ}_{1}$ coating, $\mathbf{b}, \mathbf{c ~ H Z}$ at higher magnification, $\mathrm{HA}$ rods are visible and rectangle indicates nanoparticle deposition, $\mathbf{d}$ EDS mapping of zirconium, e cross section of $\mathrm{HZ}_{1}$ coating
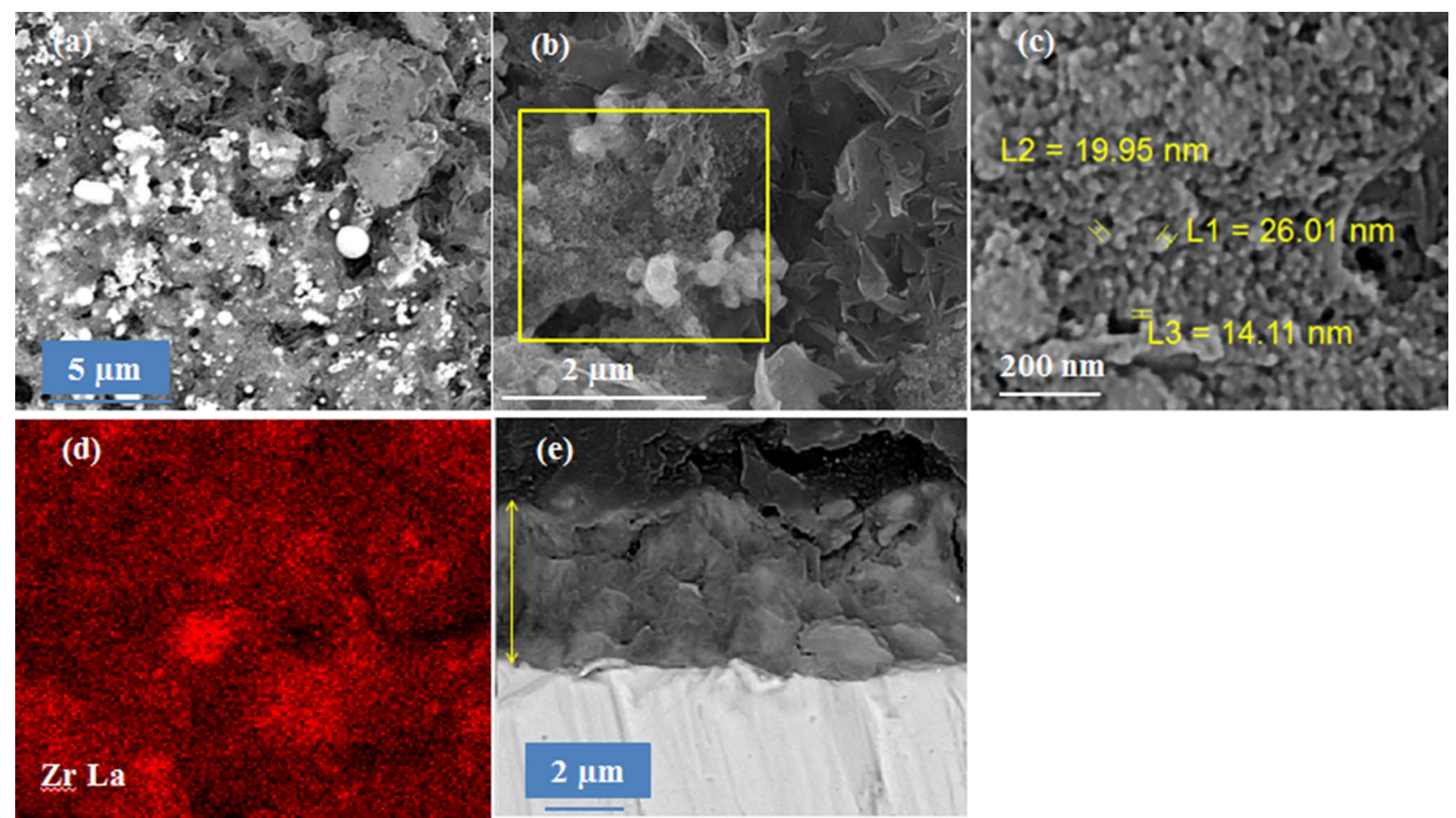

Fig. 8 FESEM images of $\mathrm{HZ}_{2}$ coating; a $\mathrm{HZ}_{2}$ coating showing film forming of hydroxyapatite and zirconia agglomeration, $\mathbf{b}, \mathbf{c ~ H Z}$ at higher magnification showing zirconia particles deposition (rectan- gle) and hydroxyapatite continues film, d EDS mapping of zirconium, e cross section of the $\mathrm{HZ}_{2}$ coating 
is prepared in Table 4. It should be taken into account that, EDS measurements were done in all the area of 15.0 $\mathrm{Kx}$ magnification ( $2 \mu \mathrm{m}$ scale) and two measurements were done for each sample (because of the coincidence of results, no more measurement done). Based on EDS results, the $\mathrm{Ca} / \mathrm{P}$ molar ratio in all the coatings is in the acceptable range of hydroxyapatite and increasing nanoparticle concentration in the solution results more nanoparticle deposition in the coating.

\subsection{Electrochemical study}

The electrochemical corrosion behavior of bare substrate and different coatings was analyzed by potentiodynamic method and the results are illustrated in Fig. 9 and reported in Table 5. There are two major electrochemical parameters that can be extracted from polarization curves, $\mathrm{E}_{\text {corr }}$ (thermodynamic parameter) and $\mathrm{i}_{\text {corr }}$ (kinetically parameter). These two parameters are helpful to analyze and compare the corrosion behavior of samples in a similar

Table 4 EDS results of $\mathrm{Ca} / \mathrm{P}$ molar ratio and $w \mathrm{t} \%$ of $\mathrm{Ti}$ and $\mathrm{Zr}$ in coatings

\begin{tabular}{llll}
\hline & $\mathrm{Ca} / \mathrm{P}(\mathrm{M} / \mathrm{M})$ & $\mathrm{Ti}(\mathrm{wt} \%)$ & $\mathrm{Zr}(\mathrm{wt} \%)$ \\
\hline $\mathrm{HA}$ & 1.47 & - & - \\
$\mathrm{HT}_{1}$ & 1.61 & 4.21 & - \\
$\mathrm{HT}_{2}$ & 1.53 & 7.50 & - \\
$\mathrm{HZ}_{1}$ & 1.55 & - & 8.06 \\
$\mathrm{HZ}_{2}$ & 1.42 & - & 17.7 \\
\hline
\end{tabular}

Table 5 Polarization parameters of bare substrate and different coatings

\begin{tabular}{lllll}
\hline & $\begin{array}{l}\mathrm{E}_{\text {corr }}(\mathrm{V} \text { vs } \\
\mathrm{SCE})\end{array}$ & $\mathrm{i}_{\text {corr }}\left(\mu \mathrm{A} / \mathrm{cm}^{2}\right)$ & $\mathrm{b}_{\mathrm{A}}(\mathrm{V} / \mathrm{dec})$ & Porosity $(\%)$ \\
\hline $\begin{array}{l}\text { Bare sub- } \\
\text { strate }\end{array}$ & -0.45 & 1.5 & 0.17 & - \\
$\mathrm{HA}$ & -0.41 & 0.09 & - & 46 \\
$\mathrm{HT}_{1}$ & -0.36 & 0.08 & & 26 \\
$\mathrm{HT}_{2}$ & -0.34 & 0.10 & - & 22 \\
$\mathrm{HZ}_{1}$ & -0.37 & 0.07 & & 32 \\
$\mathrm{HZ}_{2}$ & -0.23 & 0.08 & - & 5 \\
\hline
\end{tabular}

condition $[2,3,16,52,53]$. Based on Fig. 9, comparing the bare substrate and coated samples, the polarization curves of coated samples were shifted towards the region of lower current density, which means that coating with pure hydroxyapatite and composite coatings increases corrosion resistance and durability of substrate in simulated body fluid. The corrosion current density of bare substrate is $1.5 \mu \mathrm{A} / \mathrm{cm}^{2}$, while the $\mathrm{i}_{\text {corr }}$ of the $\mathrm{HA}, \mathrm{HT}$ and $\mathrm{HZ}$ coatings are below $0.1 \mu \mathrm{A} / \mathrm{cm}^{2}$ (specific data available in Table 5). To the best of our knowledge, corrosion current densities obtained by $\mathrm{HA}, \mathrm{HT}$ and $\mathrm{HZ}$ coatings are lower than similar previous results in the literature $[3,4]$. This means that the deposited coatings have more corrosion resistance than previous studies in simulated body fluid. It should be noted that by increasing nanoparticle concentration a distinct trend is not observed and $i_{\text {corr. }}$ of composite coatings does not obey a specific trend. According to Table 5, the $\mathrm{E}_{\text {corr }}$ of the substrate is the most negative one and $\mathrm{E}_{\text {corr. }}$.
Fig. 9 Potentiodynamic polarization curves for a bare substrate, b HA, $\mathbf{c ~ H T}{ }_{1}, \mathbf{d ~ H T} 2$, e $\mathrm{HZ}_{1}$ and $\mathbf{f} \mathrm{HZ}_{2}$ coatings in SBF solution at $37^{\circ} \mathrm{C}$

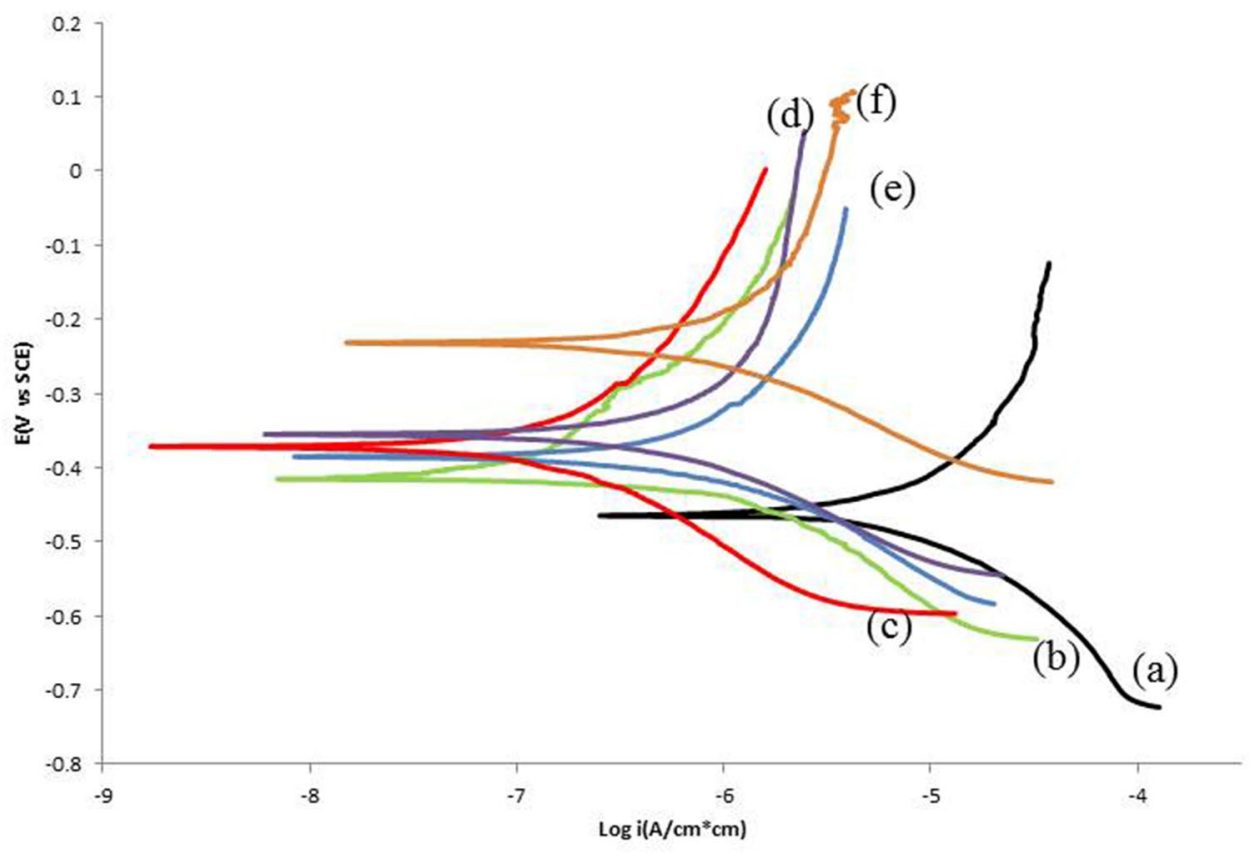


of the $\mathrm{HZ}_{2}$ coating is the most positive one. Composite coatings ( $\mathrm{HT}$ and $\mathrm{HZ}$ coatings) have more positive corrosion potential than the pure HA and the bare substrate, meaning less corrosion activity of composite coatings $[16,53]$. More negative $E_{\text {corr }}$ means wider anodic potential range and more affinity to be corroded, therefore, uncoated substrate shows more anodic behavior rather than coated substrates at the same condition (conditions of this study). The electrochemical behavior of a coating is a result of different parameters, for example: uniformity and structure of the coating [51], the morphology [54], the thickness of coating [35] and compositing agent [3]. As discussed previously, although composite coatings have lower thickness and smaller microstructure dimension, the results of the polarization tests show that compositing has promoted the electrochemical behavior of hydroxyapatite. The enhanced electrochemical properties in composite coatings can be related to: (a) the bioinert behavior of $\mathrm{ZrO}_{2}$ [55], (b) more compacted and uniform microstructure, specially film forming morphology of $\mathrm{HZ}$ coatings and less porosity in composite coatings [51,56], (c) the presence of nanoparticles in matrix structure which bans ion/electron exchange reactions of the coating. Open porosity means a pore that exists throughout the substrate-coating interface to the coating-solution interface [33]. As described previously, the mixed potential reached by the couple is given by Eq. 2. The porosity of HA, HT and $\mathrm{HZ}$ coatings is evaluated and represented in Table 5. According to porosity values, porosity of the coating is decreased by adding nanoparticle, increasing the concentration of nanoparticle results in the porosity reduction and the lowest estimated porosity is for $\mathrm{HZ}_{2}$ coating equal to $5 \%$ which is in accordance with FESEM observations. Of note is that generally a low value of coating porosity results in a better corrosion resistance [52], maybe this is another reason for increased electrochemical properties of composite coatings. Finally, the electrochemical study of synthesized coatings suggest that $\mathrm{HA}, \mathrm{HT}$ and $\mathrm{HZ}$ coatings of this study show great corrosion resistance against simulated body fluid solution and protect the substrate. Porosity, $\mathrm{E}_{\text {corr }}$ and $\mathrm{i}_{\text {corr }}$ of the bare substrate and different coatings are represented in Table 5.

\subsection{In-vitro test}

There are key parameters to choose and use orthopedic implants. For example: bioactivity, natural bone nucleation and growth on the orthopedic implant are key parameters that accelerate injury treatment and reduce heal time [7]. Bioactivity can be evaluated by simulated in vitro tests such as immersion test in SBF solution. Immersion test was done for $\mathrm{HA}, \mathrm{HT}$ and $\mathrm{HZ}$ coatings for 30 days at $37^{\circ} \mathrm{C}$. Figures 10 , 11 and 12 illustrate the surface morphology of coatings after immersion. When soaking hydroxyapatite in simulated body fluid, two major processes occur during immersion period; (1) HA dissolution (due to low crystallinity of HA) and (2) HA precipitation [3,31]. The surface morphology of pure HA in Fig. 10 consists of two different morphologies; one is apatite particles formed during immersion in SBF, the other one is hydroxyapatite plates that were electrodeposited [57]. In Fig. 10b HA coating is magnified and a compact structure of apatite deposits is clear that covers all the surface of electrodeposited HA. As seen in Fig. 10b, porosity is decreased; maybe this means that the hydroxyapatite particles formed during immersion cover porosities of primary HA. Regarding Fig. 10 the deposited apatite particles are nanometric (below $100 \mathrm{~nm}$ ) and submicron (0.02-0.2 $\mu \mathrm{m}$ ). Figure 11 demonstrates the surface morphology of $\mathrm{HT}_{1}$ and $\mathrm{HT}_{2}$ coatings that represents vigorous changes than Fig. 10. As
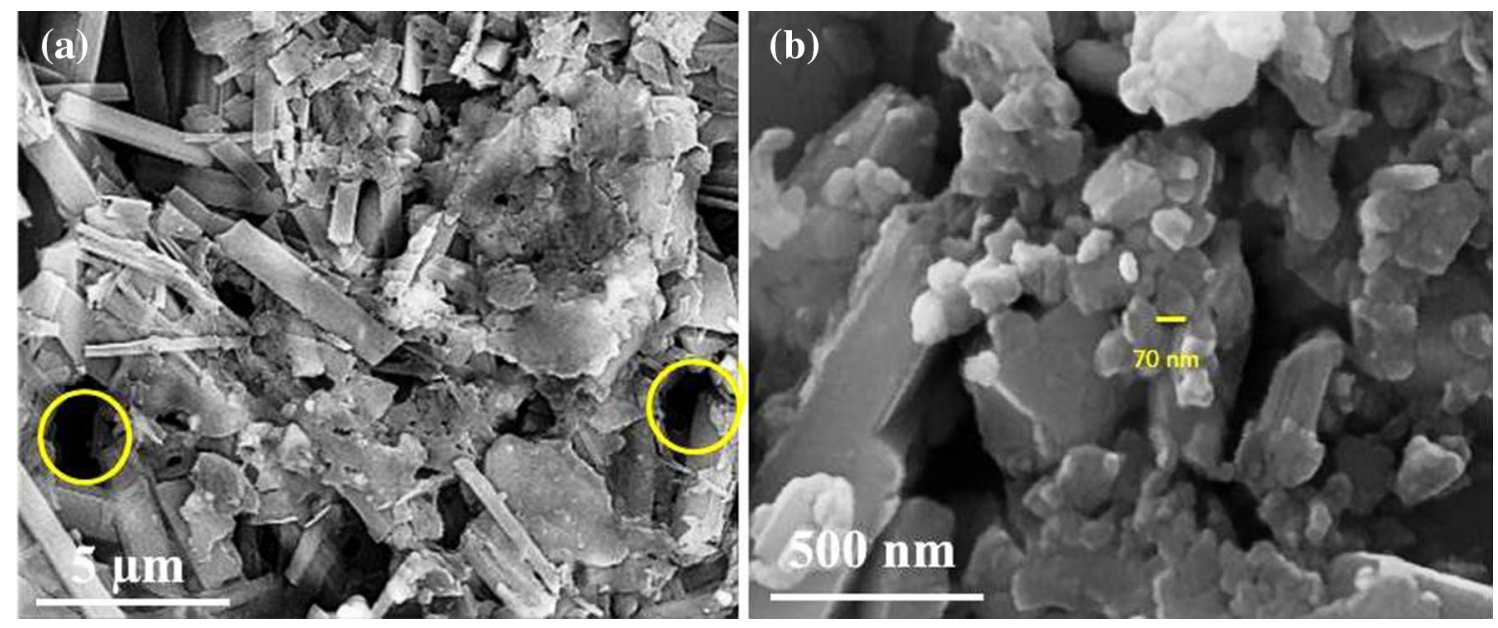

Fig. 10 FESEM images of HA after 30 days immersion in SBF: a showing primary HA, natural HA and visible porosities (circles), b higher magnification showing compact HA particles and dimensions of HA deposits 

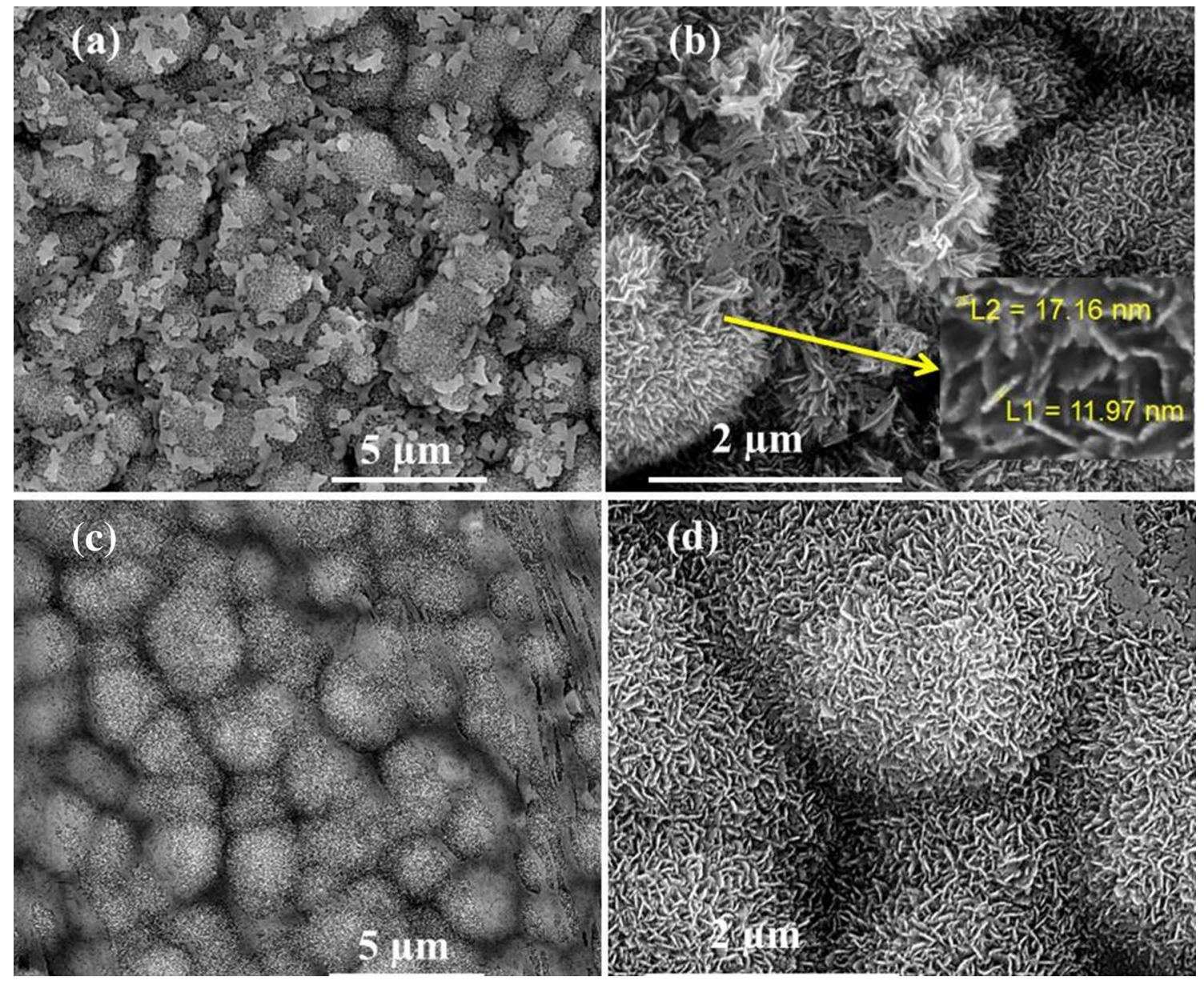

Fig. 11 FESEM micrographs of $\mathrm{HT}$ coatings after 30 days immersion in SBF: $\mathbf{a}, \mathbf{b} \mathrm{HT}_{1}, \mathbf{c}, \mathbf{d ~ H T}$ coatings showing enhanced bioactive behavior and surface coverage with natural deposits

observed in Fig. 11, bone-like apatite deposits $[58,59]$ cover the entire surface of the HT coatings and new morphology of deposited particles is found, called sponge-like HA [60]. This extreme increase in bioactivity maybe is related to the plate size decreasing and the appearance of needle-like morphology that prepares more effective contact surface with SBF. Furthermore, the addition of titania nanoparticles may increase bioactivity: (1) titania is bioactive, (2) nanoparticles increases nucleation sites, resulting more bioactivity $[46,48]$. As seen in Fig. 12, the HZ composite coatings show bioactive behavior and new morphology of apatite deposits is formed, sponge-like particles are visible in Fig. 12b. Sponge-like particles are more compacted in $\mathrm{HZ}_{2}$ coating and quantity of deposits is increased in $\mathrm{HZ}_{2}$ coating. Further evaluation of Fig. 12 reveals that $\mathrm{ZrO}_{2}$ particles are bioinert and apatite deposits do not form on these particles, which is in accordance to the literature [55] and the growth of the primary (electrodeposited) HA plates has occurred during immersion in SBF (appointed with elliptic). According to Figs. 10, 11 and 12, two points can be appointed: (1) the morphology of apatite deposits formed on $\mathrm{HZ}$ coatings is something between apatite deposits formed on $\mathrm{HA}$ and $\mathrm{HT}$ samples, (2) quantity of the deposits formed on $\mathrm{HZ}$ coatings is between the HA and $\mathrm{HT}$ samples, too.

Comparing $\mathrm{HA}, \mathrm{HT}$ and $\mathrm{HZ}$ coatings, composite coatings more bioactive behavior because more deposits are formed during immersion in SBF, which can be explained by nanostructure of composite coatings [51]. Furthermore, the observed differences in the morphology and the quantity of apatite deposits formed during immersion in SBF, may be due to the different morphologies and the chemical compositions of $\mathrm{HA}, \mathrm{HT}$ and $\mathrm{HZ}$ composite coatings. 

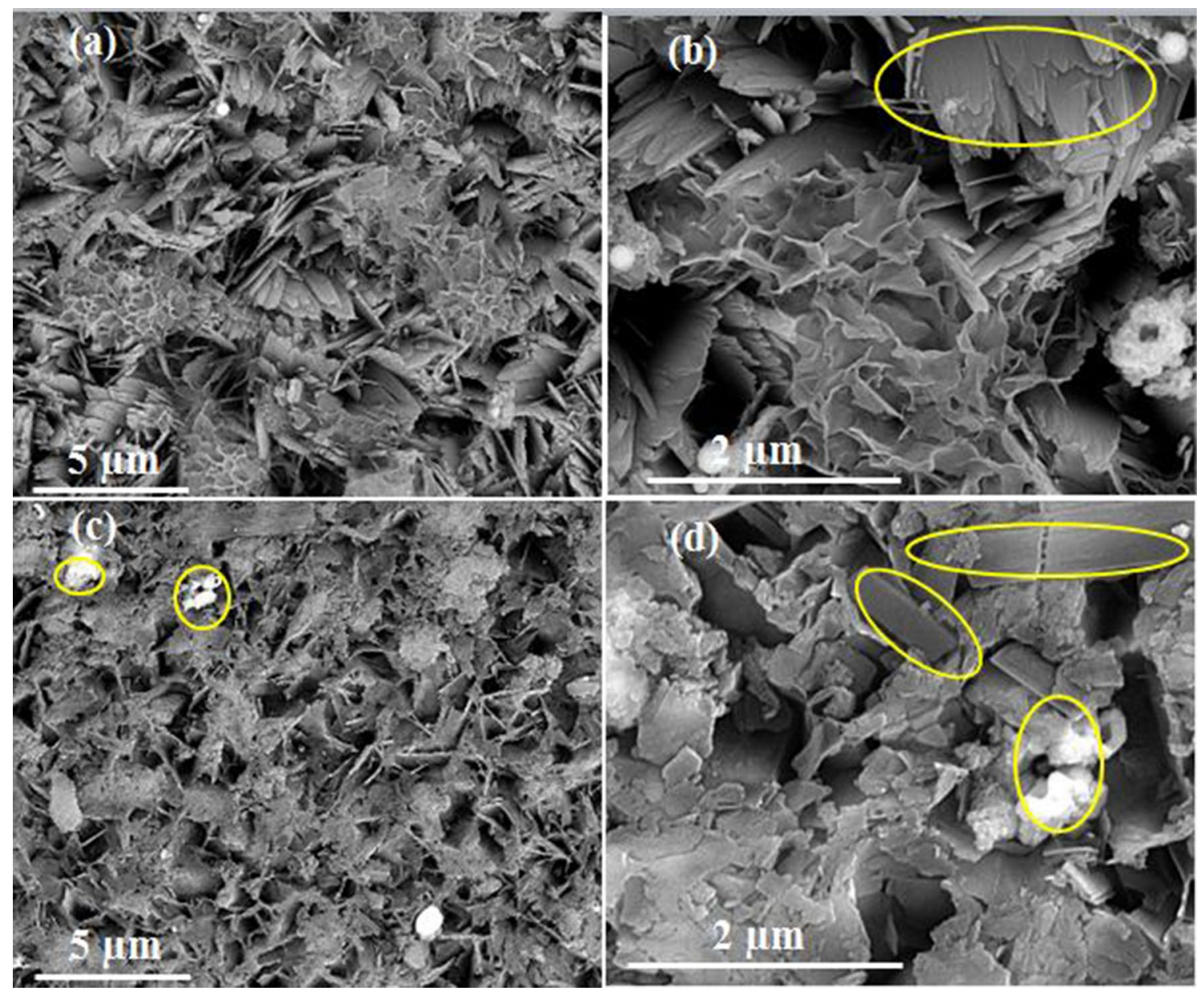

Fig. 12 FESEM images of $\mathrm{HZ}$ coatings after 30 days immersion in SBF: $\mathbf{a}, \mathbf{b} \mathrm{HZ}$ and $\mathbf{c}, \mathbf{d} \mathrm{HZ}_{2}$ coatings. Natural deposits are visible and ellipses show bioinert zirconia particles and grown primary hydroxyapatite plates

\section{Conclusion}

In summary, we have presented a merged electrodeposition method to prepare pure hydroxyapatite and composite coatings. Titania and zirconia were successfully used as compositing agent. The results show that adding titania or zirconia as compositing agent changes the behavior of hydroxyapatite matrix and increasing the content of nanoparticles toughens up the variations. In composite coatings, hydroxyapatite characteristics and different parameters such as thickness, the crystallinity of hydroxyapatite (Xc), morphology, the corrosion resistivity and the bioactivity of coatings have been changed. The authors provisionally suggest that these changes are the result of adding nanoparticles to the electrodeposition solution. Both types of composite coatings have superior properties than hydroxyapatite coating. The thickness of composite coatings is lower than pure HA. The crystallinity of hydroxyapatite increased in composite coatings and the highest value of $\mathrm{Xc}$ was for $\mathrm{HZ}_{2}$ coating equal to $86 \%$. Interestingly, new morphologies of $\mathrm{HA}$ is observed in $\mathrm{HT}$ and $\mathrm{HZ}$ coatings and nanoparticles deposition is clearly seen. Based on the electrochemical test results, coating with pure and composite coatings reduces the corrosion current density of the bare substrate and composite coatings have more positive effect on the corrosion potential of the substrate. Regarding FESEM images hydroxyapatite and composite coatings deposited by this procedure are bioactive and the bioactivity behavior of $\mathrm{HA}, \mathrm{HT}$ and $\mathrm{HZ}$ coatings is different. While our findings are not extensible toward a wider window of nanoparticles and additives, we hope that the fundamental understanding achieved in this work will pave the way for further discovery efforts to find new compositing materials to make hydroxyapatite composite coatings. 


\section{Compliance with ethical standards}

Conflict of interest The authors whose names are listed immediately below certify that they have NO affiliations with or involvement in any organization or entity with any financial interest (such as honoraria; educational grants; participation in speakers' bureaus; membership, employment, consultancies, stock ownership, or other equity interest; and expert testimony or patent-licensing arrangements), or non-financial interest (such as personal or professional relationships, affiliations, knowledge or beliefs) in the subject matter or materials discussed in this manuscript.

\section{References}

1. Breme J, Zhou Y, Groh L (1995) Development of a titanium alloy suitable for an optimized coating with hydroxyapatite. Biomaterials 16(3):239-244

2. Huang $Y$ et al (2016) Strontium and copper co-substituted hydroxyapatite-based coatings with improved antibacterial activity and cytocompatibility fabricated by electrodeposition. Ceram Int 42(10):11876-11888

3. Shojaee P, Afshar A (2015) Effects of zirconia content on characteristics and corrosion behavior of hydroxyapatite $/ \mathrm{ZrO}_{2}$ biocomposite coatings codeposited by electrodeposition. Surf Coat Technol 262:166-172

4. Liu D-M, Yang Q, Troczynski T (2002) Sol-gel hydroxyapatite coatings on stainless steel substrates. Biomaterials 23(3):691-698

5. Song YW, Shan DY, Han EH (2008) Electrodeposition of hydroxyapatite coating on AZ91D magnesium alloy for biomaterial application. Mater Lett 62(17):3276-3279

6. Suzuki $O$ et al (2006) Bone formation enhanced by implanted octacalcium phosphate involving conversion into $\mathrm{Ca}$-deficient hydroxyapatite. Biomaterials 27(13):2671-2681

7. Venkateswarlu K et al (2012) Fabrication of corrosion resistant, bioactive and antibacterial silver substituted hydroxyapatite/ titania composite coating on Cp Ti. Ceram Int 38(1):731-740

8. Chou B-Y, Chang E (1999) Microstructural characterization of plasma-sprayed hydroxyapatite- $10 \mathrm{wt} \% \mathrm{ZrO}_{2}$ composite coating on titanium. Biomaterials 20(19):1823-1832

9. Lee $\mathrm{JH}$ et al (2013) In vitro and in vivo evaluation of the bioactivity of hydroxyapatite-coated polyetheretherketone biocomposites created by cold spray technology. Acta Biomater 9(4):6177-6187

10. Cotell C (1993) Pulsed laser deposition and processing of biocompatible hydroxylapatite thin films. Appl Surf Sci 69(1-4):140-148

11. Li H, Khor KA, Cheang P (2002) Titanium dioxide reinforced hydroxyapatite coatings deposited by high velocity oxy-fuel (HVOF) spray. Biomaterials 23(1):85-91

12. Ducheyne $P$ et al (1990) Calcium phosphate ceramic coatings on porous titanium: effect of structure and composition on electrophoretic deposition, vacuum sintering and in vitro dissolution. Biomaterials 11(4):244-254

13. Ripamonti U, Roden LC, Renton LF (2012) Osteoinductive hydroxyapatite-coated titanium implants. Biomaterials 33(15):3813-3823

14. Narayanan R et al (2008) Calcium phosphate-based coatings on titanium and its alloys. J Biomed Mater Res B Appl Biomater 85(1):279-299

15. Ahn $\mathrm{H}$ et al (2008) A study about the bio-compatibility of $\mathrm{Ti}-8 \mathrm{Ta}-3 \mathrm{Nb}$ alloys with surface modification. Surf Coat Technol 202(22-23):5779-5783
16. Huang $Y$ et al (2017) Nanotube-formed Ti substrates coated with silicate/silver co-doped hydroxyapatite as prospective materials for bone implants. J Alloys Compd 697((Supplement C)):182-199

17. Viswanathan $V$ et al (2006) Challenges and advances in nanocomposite processing techniques. Mater Sci Eng R Rep 54(5):121-285

18. Zhitomirsky I (2002) Cathodic electrodeposition of ceramic and organoceramic materials. Fundamental aspects. Adv Colloid Interface Sci 97(1):279-317

19. Royer P, Rey C (1991) Calcium phosphate coatings for orthopaedic prosthesis. Surf Coat Technol 45(1-3):171-177

20. Pang X, Zhitomirsky I (2005) Electrodeposition of composite hydroxyapatite-chitosan films. Mater Chem Phys 94(2):245-251

21. Chen $\mathrm{Q}$ et al (2013) Alginate/Bioglass composite coatings on stainless steel deposited by direct current and alternating current electrophoretic deposition. Surf Coat Technol 233:49-56

22. Huang $Y$ et al (2013) Corrosion behavior and biocompatibility of strontium and fluorine co-doped electrodeposited hydroxyapatite coatings. Appl Surf Sci 282:456-462

23. Huang $Y$ et al (2016) Improving the bioactivity and corrosion resistance properties of electrodeposited hydroxyapatite coating by dual doping of bivalent strontium and manganese ion. Surface Coat Technol 291:205-215

24. Kim D-Y et al (2009) Formation of hydroxyapatite within porous $\mathrm{TiO}_{2}$ layer by micro-arc oxidation coupled with electrophoretic deposition. Acta Biomater 5(6):2196-2205

25. Kodama A et al (2009) Bioactivation of titanium surfaces using coatings of $\mathrm{TiO}_{2}$ nanotubes rapidly pre-loaded with synthetic hydroxyapatite. Acta Biomater 5(6):2322-2330

26. Balamurugan A et al (2007) Electrochemical and structural characterisation of zirconia reinforced hydroxyapatite bioceramic sol-gel coatings on surgical grade $316 \mathrm{~L}$ SS for biomedical applications. Ceram Int 33(4):605-614

27. Poorraeisi M, Afshar A (2018) The study of electrodeposition of hydroxyapatite- $\mathrm{ZrO}_{2}-\mathrm{TiO}_{2}$ nanocomposite coatings on 316 stainless steel. Surf Coat Technol 339:199-207

28. Brook I et al (2012) Biological evaluation of nano-hydroxyapatite-zirconia $\left(\mathrm{HA}-\mathrm{ZrO}_{2}\right)$ composites and strontiumhydroxyapatite $(\mathrm{Sr}-\mathrm{HA})$ for load-bearing applications. J Biomater Appl 27(3):291-298

29. Goudarzi M et al (2014) Development of electrophoretically deposited hydroxyapatite coatings on anodized nanotubular $\mathrm{TiO}_{2}$ structures: corrosion and sintering temperature. Appl Surf Sci 301:250-257

30. Kim H-W et al (2003) Porous $\mathrm{ZrO}_{2}$ bone scaffold coated with hydroxyapatite with fluorapatite intermediate layer. Biomaterials 24(19):3277-3284

31. Thanh DTM et al (2013) Controlling the electrodeposition, morphology and structure of hydroxyapatite coating on $316 \mathrm{~L}$ stainless steel. Mater Sci Eng C 33(4):2037-2045

32. Gopi D, Indira J, Kavitha L (2012) A comparative study on the direct and pulsed current electrodeposition of hydroxyapatite coatings on surgical grade stainless steel. Surf Coat Technol 206(11-12):2859-2869

33. Mansfeld F (1971) Area relationships in galvanic corrosion. Corrosion 27(10):436-442

34. Kokubo T, Takadama $\mathrm{H}$ (2006) How useful is SBF in predicting in vivo bone bioactivity? Biomaterials 27(15):2907-2915

35. Zhang J et al (2015) Study on the effect of the coating thickness on corrosion behavior of AZ91D magnesium alloy in m-SBF. Int J Electrochem Sci 10:6002

36. Low CTJ, Wills RGA, Walsh FC (2006) Electrodeposition of composite coatings containing nanoparticles in a metal deposit. Surf Coat Technol 201(1):371-383 
37. Eliaz N, Sridhar TM (2008) Electrocrystallization of hydroxyapatite and its dependence on solution conditions. Cryst Growth Des 8(11):3965-3977

38. Fox RC et al (2013) Effects of size and concentration of gold nanoparticles on diffusion coefficient of redox species Fe (CN) 64-. ECS Electrochem Lett 2(10): $\mathrm{H} 40-\mathrm{H} 42$

39. Qiu D et al (2011) Preparation and characterization of hydroxyapatite/titania composite coating on $\mathrm{NiTi}$ alloy by electrochemical deposition. Surf Coat Technol 205(10):3280-3284

40. Metoki N et al (2014) Hydroxyapatite coatings electrodeposited at near-physiological conditions. Mater Lett 119:24-27

41. Shirkhanzadeh M (1998) Direct formation of nanophase hydroxyapatite on cathodically polarized electrodes. J Mater Sci Mater Med 9(2):67-72

42. Brown W (1966) Crystal growth of bone mineral. Clin Orthop Relat Res 44:205-220

43. Lakstein D et al (2009) Enhanced osseointegration of gritblasted, $\mathrm{NaOH}$-treated and electrochemically hydroxyapatite-coated Ti-6Al-4V implants in rabbits. Acta Biomater 5(6):2258-2269

44. Wang Y et al (2014) $\mathrm{TiO}_{2}$ (B) nanosheets mediate phase selective synthesis of $\mathrm{TiO}_{2}$ nanostructured photocatalyst. Appl Surf Sci 292:937-943

45. Basahel SN et al (2015) Influence of crystal structure of nanosized $\mathrm{ZrO}_{2}$ on photocatalytic degradation of methyl orange. Nanoscale Res Lett 10(1):73

46. Wu W, Zhuang H, Nancollas GH (1997) Heterogeneous nucleation of calcium phosphates on solid surfaces in aqueous solution. J Biomed Mater Res Part A 35(1):93-99

47. Hou X, Choy KL, Leach SE (2007) Processing and in vitro behavior of hydroxyapatite coatings prepared by electrostatic spray assisted vapor deposition method. J Biomed Mater Res Part A 83(3):683-691

48. Klokkevold PR et al (1997) Osseointegration enhanced by chemical etching of the titanium surface. A torque removal study in the rabbit. Clin Oral Implants Res 8(6):442-447
49. Bahrololoom $M$ et al (2009) Characterisation of natural hydroxyapatite extracted from bovine cortical bone ash. J Ceram Process Res 10(2):129-138

50. Johnson $\mathrm{L}$ et al (2014) The role of $\mathrm{LiO}_{2}$ solubility in $\mathrm{O}_{2}$ reduction in aprotic solvents and its consequences for $\mathrm{Li}-\mathrm{O}_{2}$ batteries. Nat Chem 6(12):1091

51. Meng EC et al (2011) Effect of electrodeposition modes on surface characteristics and corrosion properties of fluorine-doped hydroxyapatite coatings on $\mathrm{Mg}-\mathrm{Zn}-\mathrm{Ca}$ alloy. Appl Surf Sci 257(11):4811-4816

52. Darband GB, Afshar A, Aliabadi A (2016) Zn-Ni Electrophosphating on galvanized steel using cathodic and anodic electrochemical methods. Surf Coat Technol 306:497-505

53. Stansbury EE, Buchanan RA (2000) Fundamentals of electrochemical corrosion. ASM international, Russell Township

54. Wang $\mathrm{H}$ et al (2007) The effect of pre-processing and grain structure on the bio-corrosion and fatigue resistance of magnesium alloy AZ31. Adv Eng Mater 9(11):967-972

55. Qiu D, Wang A, Yin Y (2010) Characterization and corrosion behavior of hydroxyapatite/zirconia composite coating on NiTi fabricated by electrochemical deposition. Appl Surf Sci 257(5):1774-1778

56. Kwok CT et al (2009) Characterization and corrosion behavior of hydroxyapatite coatings on Ti6AI4V fabricated by electrophoretic deposition. Appl Surf Sci 255(13):6736-6744

57. Guo X et al (2011) Controlled synthesis of hydroxyapatite crystals templated by novel surfactants and their enhanced bioactivity. New J Chem 35(3):663-671

58. Li X et al (2018) Stabilization of Ca-deficient hydroxyapatite in biphasic calcium phosphate ceramics by adding alginate to enhance their biological performances. J. Mater. Chem. B 6(1):84-97

59. Munir G et al (2011) The pathway to intelligent implants: osteoblast response to nano silicon-doped hydroxyapatite patterning. J R Soc Interface 8:678

60. Duan $S$ et al (2015) Microstructure evolution and mechanical properties improvement in liquid-phase-sintered hydroxyapatite by laser sintering. Materials 8(3):1162-1175 